University of Wollongong

Research Online

Faculty of Engineering and Information

Faculty of Engineering and Information

Sciences - Papers: Part B

Sciences

2018

Effects of fouling on separation performance by forward osmosis: the role of specific organic foulants

Lei Zheng

University of Wollongong, Iz965@uowmail.edu.au

William E. Price

University of Wollongong, wprice@uow.edu.au

Long D. Nghiem

University of Technology, Sydney, longn@uow.edu.au

Follow this and additional works at: https://ro.uow.edu.au/eispapers1

Part of the Engineering Commons, and the Science and Technology Studies Commons

Research Online is the open access institutional repository for the University of Wollongong. For further information contact the UOW Library: research-pubs@uow.edu.au 


\title{
Effects of fouling on separation performance by forward osmosis: the role of specific organic foulants
}

\author{
Abstract \\ In this study, forward osmosis (FO) membranes and fouling solutions were systematically characterized \\ to elucidate the effects of organic fouling on the rejection of two pharmaceutically active compounds, \\ namely, sulfamethoxazole and carbamazepine. Municipal wastewater resulted in a more severe flux \\ decline compared to humic acid and sodium alginate fouling solutions. This result is consistent with the \\ molecular weight distribution of these foulant solutions. Liquid chromatography with organic carbon \\ detection analysis shows that municipal wastewater consists of mostly low molecular weight acids and \\ neutrals, which produce a more compact cake layer on the membrane surface. By contrast, humic acid \\ and sodium alginate consist of large molecular weight humic substances and biopolymers, respectively. \\ The results also show that membrane fouling can significantly alter the membrane surface charge and \\ hydrophobicity as well as the reverse salt flux. In particular, the reverse salt flux of a fouled membrane \\ was significantly higher than that under clean conditions. Although the rejection of sulfamethoxazole and \\ carbamazepine by FO membrane was high, a discernible impact of fouling on their rejection could still be \\ observed. The results show that size exclusion is a major rejection mechanism of both sulfamethoxazole \\ and carbamazepine. However, they respond to membrane fouling differently. Membrane fouling results in \\ an increase in sulfamethoxazole rejection while carbamazepine rejection decreases due to membrane \\ fouling. \\ Disciplines \\ Engineering | Science and Technology Studies

\section{Publication Details} \\ Zheng, L., Price, W. E. \& Nghiem, L. D. (2019). Effects of fouling on separation performance by forward \\ osmosis: the role of specific organic foulants. Environmental Science and Pollution Research, 26 \\ 33758-33769.
}


1

2

3

4

5

6

9

10

Effects of fouling on separation performance by forward osmosis: the role of specific organic foulants

\author{
Revised Manuscript Submitted to \\ Environmental Science and Pollution Research
}

Lei Zheng ${ }^{1}$, William E. Price ${ }^{1}$, and Long D. Nghiem ${ }^{2, *}$

${ }^{1}$ Strategic Water Infrastructure Laboratory, University of Wollongong, Wollongong, NSW 2522, Australia

${ }^{2}$ Centre for Technology in Water and Wastewater, University of Technology Sydney, Ultimo NSW 2007, Australia

$11 *$ Corresponding author: Long D. Nghiem, Email: Duclong.Nghiem@uts.edu.au, Ph +61 29514 $12 \quad 2625$ 


\section{Abstract}

In this study, forward osmosis (FO) membranes and fouling solutions were systematically characterized to elucidate the effects of organic fouling on the rejection of two pharmaceutically active compounds namely sulfamethoxazole and carbamazepine. Municipal wastewater resulted in a more severe flux decline compared to humic acid and sodium alginate fouling solutions. This result is consistent with the molecular weight distribution of these foulant solutions. Liquid chromatography with organic carbon detection analysis shows that municipal wastewater consists of mostly low molecular weight acids and neutrals, which result in a more compact cake layer on the membrane surface. By contrast, humic acid and sodium alginate consist of large molecular weight humic substances and biopolymers, respectively. The results also show that membrane fouling can significantly alter the membrane surface charge and hydrophobicity as well as the reverse salt flux. In particular, the reverse salt flux of a fouled membrane was significantly higher than that under clean conditions. Although the rejection of sulfamethoxazole and carbamazepine by FO membrane was high, a discernible impact of fouling on their rejection can still be observed. The results show that size exclusion is the main rejection mechanism of both sulfamethoxazole and carbamazepine. However, they respond to membrane fouling differently. Membrane fouling results in an increase in sulfamethoxazole rejection. By contrast, carbamazepine rejection decreases due to membrane fouling.

Keywords Forward osmosis, Sulfamethoxazole, Carbamazepine, Organic fouling, Reverse salt flux, Municipal wastewater. 


\section{Introduction}

Water scarcity is an increasingly pervasive problem worldwide and has been further exacerbated by population growth, energy shortage and climate change (Shannon et al. 2008). In recent years, the occurrence of micropollutants, such as hormones, pharmaceutically active compounds (PhACs), industrial chemicals, and pesticides, in wastewater has received significant attention from the scientific community because of their potential impacts on human health and the environment (Luo et al. 2014). Conventional wastewater treatment is not capable of removing all of these micropollutants. Thus, they are ubiquitous in most secondary treated effluent and surface water (Chen \&Ying 2015, Luo et al. 2014). Notable examples are sulfamethoxazole (SMX) and carbamazepine (CBZ), which are prescribed antibiotic and anti-epileptic pharmaceuticals respectively and occur often in municipal wastewater (Hernando et al. 2006, Yoon et al. 2010). Recent data suggest that these micropollutants may induce chronic biological effects on non-target organisms (including humans) even at low concentrations (Carlson et al. 2013, Schwarzenbach et al. 2006).

Several membrane processes (e.g. nanofiltration (NF), reverse osmosis (RO) and membrane bioreactor) can be used to effectively remove micropollutants during water and wastewater treatment (Luo et al. 2016, Nghiem \&Coleman 2008, Simon et al. 2009, Yang et al. 2016). However, high energy consumption, high fouling propensity and issues associated with brine discharge have all been identified as major drawbacks of these membrane based technologies (Lee et al. 2010, McGinnis \&Elimelech 2007, Zhao et al. 2012). In this context, there is an emerging membrane technology, namely, forward osmosis (FO). In FO, a natural osmotic pressure from a highly concentrated draw solution is the driving force for water transport from the feed solution through a dense, semipermeable FO membrane into the draw solution (Cath et al. 2013). The low fouling propensity of FO is a major advantage of this process (Lee et al. 2010, Zhao et al. 2012). In addition, FO can be directly integrated with activated sludge treatment in the form of an osmotic membrane bioreactor (Aftab et al. 2015, Chang et al. 2017, Luo et al. 2017) and other processes (e.g. membrane distillation (Nguyen et al. 2017, Xie et al. 2013b) and reverse osmosis (Liyanaarachchi et al. 2016)) to further enhance the removal of micropollutants. 
Although several researchers have demonstrated that FO has a much lower fouling propensity compared to the pressure driven membrane treatments (Lee et al. 2010, Xie et al. 2012), any fouling layer formed can still potentially affect the rejection behavior of micropollutants. Both increases and decreases in rejection between clean and fouled membrane have been observed. Organic matter including biopolymers, humic substances and other small molecular weight organic compounds are major sources of foulants during the FO process. Biopolymer, such as sodium alginate is made up of repeating manuronic and guluronic acids. Humic substances are a mixture of heterogeneous recalcitrant macro-organic compounds that occur naturally in the environment.

Rejection of target contaminants, water flux and reverse salt flux can all be affected by membrane fouling. However, to date, there have only been a few investigations to elucidate the effect of membrane fouling during FO operation on the process performance particularly for PhACs rejection. The impacts of fouling on PhACs rejection can be attributed to several mechanisms. Valladares Linares et al., (2011) found that membrane fouling caused by natural organic matter in wastewater enhanced the rejection of ionic and neutral PhACs by altering membrane surface charge and hydrophobicity. Xie et al., (2013a, 2014a) have recently investigated the impact of colloidal fouling on the rejection of PhACs. They hypothesized that the mechanism for the rejection of PhACs by a humic acid fouled membrane was based on the membrane pore size and steric hindrance. In addition, combined fouling with organic and colloidal particles was the result of membrane pore blockage and thus enhanced steric hindrance effects. D' Haese et al., (2013) found that an alginate fouled membrane exhibited lower rejection for some micropollutants than a clean membrane. This was thought to be possibly due to cake enhanced concentration polarization arising from the cake layer formed by organic foulants.

This study aims to investigate the effect of membrane fouling caused by specific organic foulants (humic substances, sodium alginate and municipal wastewater) on the rejection of two model PhACs (i.e. sulfamethoxazole and carbamazepine) by a commercially available TFC FO membrane. Key membrane properties and the rejection behavior of the clean and fouled membranes are assessed to systematically elucidate the mechanism of different foulants on the rejection of PhACs. 


\section{Materials and Methods}

\subsection{Materials}

A flat-sheet thin film composite (TFC) FO membrane used in this study. Similar to other TFC FO membranes in the market, it consists of an ultra-thin active polyamide skin layer on the top of a microporous polysulfone supporting layer.

Municipal wastewater was obtained from a wastewater treatment plant in New South Wales, Australia. Humic acid and sodium alginate from Sigma-Aldrich (St. Louis, MO, analytical grade) were selected as model foulants to represent humic substances and polysaccharides, respectively, since they commonly occur in municipal wastewater. Deionized (DI) water was used to prepare stock solutions containing $2 \mathrm{~g} / \mathrm{L}$ of each model foulant. These stock solutions were stored in sterilized glass bottles at $-4{ }^{\circ} \mathrm{C}$.

Analytical grade sulfamethoxazole and carbamazepine from Sigma-Aldrich (St. Louis, MO, analytical grade) were selected as model PhACs. Their key physicochemical properties are presented in the Table 1. A combined stock solution containing $2 \mathrm{~g} / \mathrm{L}$ of each PhACs was prepared in pure methanol which was kept at $-18{ }^{\circ} \mathrm{C}$ in the dark and was used within one month.

Table 1 Key physicochemical properties of sulfamethoxazole and carbamazepine.

\begin{tabular}{|c|c|c|}
\hline Pharmaceutical & Sulfamethoxazole & Carbamazepine \\
\hline Structure & & \\
\hline Molecular weight (Da) & 253.3 & 236.3 \\
\hline $\mathrm{pK}_{\mathrm{a}}{ }^{1}$ & $1.7,5.8$ & 9.73 \\
\hline $\log K_{\text {ow }}^{1}$ & 0.89 & 2.45 \\
\hline Dipole moment (Debye) ${ }^{2}$ & 5.4 & 3.6 \\
\hline Stokes radius $(\mathrm{nm})$ & 0.38 & 0.37 \\
\hline Molecular length $(\mathrm{nm})^{2}$ & 1.031 & 0.891 \\
\hline Molecular width $(\mathrm{nm})^{2}$ & 0.587 & 0.529 \\
\hline Molecular depth (nm) ${ }^{2}$ & 0.526 & 0.507 \\
\hline
\end{tabular}


$115{ }^{1}$ From the SciFinder Scholar (ACS) database. ${ }^{2}$ Molecular dimensions and the dipole moment calculated using Molecular Modeling Pro Version 6.3.3 (Chem SW Inc.)

117 Analytical grade erythritol, xylose, and glucose (Sigma-Aldrich, St. Louis, MO) were used as reference organic solutes to estimate the effective pore size of membrane active layer. These organic solutes were individually dissolved in DI water to obtain a concentration of $40 \mathrm{mg} / \mathrm{L}$ (as total organic carbon (TOC)).

\subsection{Experimental systems}

122 A bench scale FO system (Fig. 1) was used. A membrane cell consists of two acrylic plastic 123 semi-cells with length, width and height of 10,5 , and $0.2 \mathrm{~cm}$, respectively. The membrane was 124 placed between the two semi-cells with an effective area of $44.65 \mathrm{~cm}^{2}$. Two gear pumps (Micropump, Vancouver, WA) were used to circulate the feed and draw solution simultaneously at a constant cross flow rate of $0.5 \mathrm{~L} / \mathrm{min}$ (corresponding to a cross-flow velocity $8.9 \mathrm{~cm} / \mathrm{s}$ ) which was monitored by two rotameters. A draw solution reservoir was placed on a digital balance (Mettler-Toledo Inc., Hightstown, NJ) and weight change was recorded every 5 minutes by a data logger. A conductivity probe (Cole-Parmer, Vernon Hills, IL) was used to measure the conductivity of the draw solution. When the draw solution conductivity deviated from the set point by $0.1 \mathrm{mS} / \mathrm{cm}$, a small volume of concentrated draw solution $(5 \mathrm{M} \mathrm{NaCl})$ was automatically added into the draw solution reservoir using a peristaltic pump to maintain a constant draw solution concentration. The concentrated draw solution reservoir was also placed on the same digital balance to avoid any interference caused by liquid transfer between the two reservoirs. 


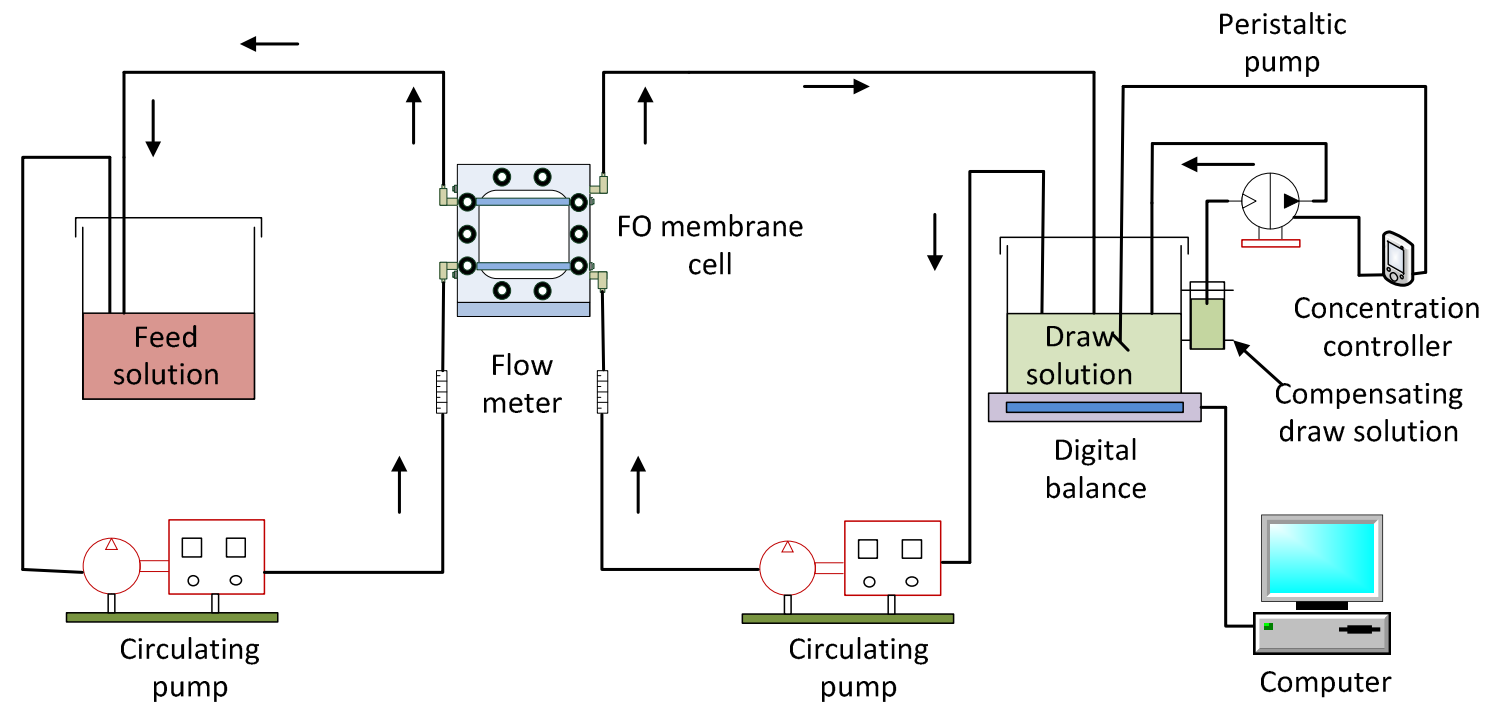

137 Fig. 1 The schematic diagram of the forward osmosis system.

138 Water permeability (A value) and salt $(\mathrm{NaCl})$ permeability (B value) were characterized according to the standard method previous described by Cath et al(Cath et al. 2013). This involves a cross-flow system consisting of a stainless steel cross flow membrane cell, a HydraCell pump (Wanner Engineering, Minneapolis, MN) and chiller (Neslab RTE7, Waltham, MA). The membrane cell had a flow channel with dimensions of length, width and height of 10, 4, and $0.2 \mathrm{~cm}$, respectively. The effective membrane area was $40 \mathrm{~cm}^{2}$. The feed solution was pressurized into the membrane cell by pump. The cross-flow rate and the hydraulic pressure were controlled by a back-pressure regulator and a bypass valve, respectively. The temperature of feed solution was maintained at $20 \pm 1{ }^{\circ} \mathrm{C}$ by the chiller equipped with a stainless steel heat exchanger. A digital flow meter (Optiflow, Palo Alto, CA) connected to a computer was used to record the permeate flux.

\subsection{Membrane characterisation}

\subsubsection{Membrane active layer transport properties}

The pure water permeability coefficient (A value) and salt $(\mathrm{NaCl})$ permeability coefficient (B value) of the membrane active layer were determined according to the standard protocol developed by Cath et al., (2013). DI water and $\mathrm{NaCl}$ solution $(2 \mathrm{~g} / \mathrm{L})$ were used as feed solutions to determine the membrane A and B values, respectively. The membrane was first compacted for 


$$
k_{f}=\frac{J_{D I}}{\ln \left\{\frac{\Delta p}{\pi_{b}-\pi_{p}} \bullet\left[1-\frac{J_{N a C l}}{J_{D I}}\right]\right\}}
$$
where $D_{s}$ is the diffusivity of the draw solute, $\pi_{D, b}$ is the bulk osmotic pressure of the draw 176

$2 \mathrm{~h}$ at the applied hydraulic pressure $(\Delta \mathrm{P}) 10$ bar and cross flow velocity of $25 \mathrm{~cm} / \mathrm{s}$ to yield a stable water flux. The water flux values of DI water $\left(\mathrm{J}_{\mathrm{DI}}\right)$ and $\mathrm{NaCl}$ solution $\left(\mathrm{J}_{\mathrm{NaCl}}\right)$ were then determined. At the end of the filtration experiment, the feed and permeate samples were collected to measure the concentration of $\mathrm{NaCl}$ for calculating the observed rejection $(R)$. The $\mathrm{A}$ and $\mathrm{B}$ values were calculated as follows:

$A=\frac{J_{D I}}{\Delta P}$

where $k_{f}$ represents the mass transfer coefficient of the channel of the cross-flow membrane cell (Cath et al. 2013). The mass transfer coefficient $k_{f}$ was calculated using the Sutzkover et al., (2000).

where $\pi_{b}$ and $\pi_{p}$ are the feed and permeate osmotic pressures, which can be calculated by their corresponding salt concentrations based on van't Hoff equation.

\subsubsection{Membrane support layer structural properties}

The membrane structure parameter, S, was experimentally obtained in the cross-flow FO setup as described above in $\mathrm{FO}$ mode (i.e. active layer facing feed solution). $\mathrm{A} \mathrm{NaCl}$ draw solution ( 0.5 M) and DI water feed solution were used. The membrane $S$ value was calculated using following equation (Cath et al. 2013):

$S=\frac{D_{s}}{J_{w}} \ln \left(\frac{B+A \pi_{D, b}}{B+J_{w}+A \pi_{F, m}}\right)$ solution, and $\pi_{F, m}$ is the osmotic pressure at the membrane surface on the feed side. 


\subsubsection{Determination of the membrane average pore radius}

The effective pore radius of membrane active layer was estimated by the three reference organic solutes previously described in section 2.1. These solutes are inert, neutral and do not adsorb onto membrane. The experiments were conducted in the cross-flow RO setup as described in section 2.2. The membrane sample was compacted for $3 \mathrm{~h}$ at 10 bar. Subsequent experiments were conducted at 5, 6, 8, 10 and 12 bar with a cross-flow velocity of $25 \mathrm{~cm} / \mathrm{s}$. At each pressure value, the RO filtration system was operated for $1 \mathrm{~h}$ before taking permeate and feed samples.

In this model, the ratio of solute radius $\left(\mathrm{r}_{\mathrm{s}}\right)$ to the membrane pore radius $\left(\mathrm{r}_{\mathrm{p}}\right), \lambda=r_{s} / r_{p}$ is related to the distribution coefficient of hard-sphere particles $(\phi)$ when only steric interactions are considered:

$\phi=(1-\lambda)^{2}$

To obtain the real rejection of the reference organic solutes $\left(\mathrm{R}_{\mathrm{r}}\right)$ from so-called sieving coefficient, $S_{a}$, the calculations below were applied:

$S_{a}=\frac{C_{L}}{C_{0}}=\frac{\phi K_{c}}{1-\exp (-P e)\left(1-\phi K_{c}\right)}$

$R_{r}=1-\frac{C_{L}}{C_{0}}=1-S_{a}=1-\frac{\phi K_{c}}{1-\exp (-P e)\left(1-\phi K_{c}\right)}$

where $\mathrm{C}_{0}$ and $\mathrm{C}_{\mathrm{L}}$ are the solute concentrations outside the pore entrance (i.e. on the membrane surface in the feed side) and pore exit (i.e. on the membrane surface in the permeate side), respectively; $\mathrm{K}_{\mathrm{c}}$ is the hydrodynamic hindrance coefficient for the conviction; and $\mathrm{Pe}$ is the membrane Peclet number, which can be defined as:

$P e=\frac{K_{c} J_{r} l_{a}}{K_{d} D}=\frac{K_{c} J_{v} l_{a}}{K_{d} D \varepsilon_{a}}$

where $K_{d}$ is the hydrodynamic hindrance coefficient diffusion; $J_{r}$ is the radial average fluid velocity in a cylindrical membrane pore, which equals to the membrane volumetric permeate flux $\left(\mathrm{J}_{\mathrm{v}}\right)$ divided by the effective porosity of the membrane active layer $\left(\varepsilon_{\mathrm{a}}\right)$; D is the StokesEinstein diffusion coefficient, $1_{\mathrm{a}}$ is the theoretical pore length (i.e. the thickness of the membrane 
active layer). Details on the calculations of $\mathrm{Pe}, \mathrm{K}_{\mathrm{c}}$ and $\mathrm{K}_{\mathrm{d}}$ have been described elsewhere (Bungay \&Brenner 1973, Nghiem et al. 2004).

Using the film theory for concentration polarization, the relation between observed rejection of organic solutes $\left(\mathrm{R}_{\mathrm{o}}\right)$ and the real rejection $\left(\mathrm{R}_{\mathrm{r}}\right)$ can be represented via:

$\ln \frac{1-R_{r}}{R_{r}}=\ln \frac{1-R_{o}}{R_{o}}-\frac{J_{v}}{k_{f}}$

where the $R_{0}$ is calculated based on the different concentrations of TOC between feed and permeate samples.

The real rejection $\left(\mathrm{R}_{\mathrm{r}}\right)$ of each reference organic solute was calculated from observed rejection $\left(\mathrm{R}_{\mathrm{o}}\right)$ by considering concentration polarization effects using Eq. (8) and the mass transfer coefficient in Eq.(3). In the pore hindrance transport model, since $\phi K_{c}$ and $\mathrm{Pe} / \mathrm{J}_{\mathrm{v}}$ are unlikely related to $\mathrm{R}_{\mathrm{r}}$, thus they can be determined by fitting the reference organic solute rejection data to the model using Eq.(7). The optimization procedures were conducted by the Excel (Solver, Microsoft). Furthermore, the parameters $\phi K_{c}$ and Pe/J $\mathrm{J}_{\mathrm{v}}$ can be expressed as a sole function of the variable $\lambda$, which is the ratio of solute radius $\left(r_{s}\right)$ to membrane pore radius $\left(r_{p}\right)$. Therefore, the membrane average pore radius can be calculated from the variable $\lambda$.

\subsubsection{Membrane surface charge and hydrophobicity}

The membrane surface charge represented by zeta potential was analyzed by a SurPASS streaming current electrokinetic analyzer (Anton Paar GmbH, Graz, Austria). Based on the Fairbrother-Mastin method (Elimelech et al. 1994), the zeta potential was calculated from the measured streaming potential data. All streaming potential measurements were performed in a background electrolyte solution containing $10 \mathrm{mM} \mathrm{KCl}$. The same electrolyte solution was used to rinse the cell thoroughly prior to automatic $\mathrm{pH}$ titration within $\mathrm{HCl}(1 \mathrm{M})$ or $\mathrm{KOH}(1 \mathrm{M})$. All measurements were conducted at room temperature $\left(\mathrm{ca} 25^{\circ} \mathrm{C}\right)$.

The membrane surface hydrophobicity was evaluated by contact angle measurement using a Rame-Hart Goniometer (Model 250, Rame-Hart, Netcong, NJ). Standard sessile drop method 
was used for analyzing contact angle. Membrane samples were air-dried in a desiccator before the analysis. Ten droplets of DI water were applied to each membrane sample and the mean values of contact angles on both sides of the droplet were evaluated.

\subsection{Forward osmosis experiments}

$\mathrm{NaCl}$ solution $(0.5 \mathrm{M})$ was used as the draw solution. The synthetic wastewater was prepared by adding either sodium alginate or humic acid to an electrolyte solution of $1 \mathrm{mM} \mathrm{CaCl}_{2}$ to obtain $200 \mathrm{mg} / \mathrm{L}$ of each of these model organic foulant. The initial volumes of the feed and draw solution were $3 \mathrm{~L}$ and $0.25 \mathrm{~L}$, respectively. All experiments were conducted in FO mode for $20 \mathrm{~h}$. The synthetic feed solutions were adjusted to the same $\mathrm{pH}$ of municipal wastewater $(\mathrm{pH} 5.5)$ by adding a small volume of either $1 \mathrm{M} \mathrm{HCl}$ or $\mathrm{NaOH}$. PhACs were introduced into the feed solution to obtain $2 \mathrm{mg} / \mathrm{L}$ of each compound. It is noted that this concentration and the typical concentration of PhACs in wastewater are too small to contribute to membrane fouling. Approximate $3 \mathrm{~mL}$ of feed and draw solution samples were collected at specific time intervals for analysis. The experiment was conducted in a temperature controlled room $\left(25 \pm 1{ }^{\circ} \mathrm{C}\right)$.

Since the concentration of PhACs during the experiment is diluted by the draw solution, a dilution factor is introduced to determine the permeate concentration:

$J_{N}=\frac{J_{t}}{J_{0}}$

$D F=\frac{V_{\text {draw }, t}}{\Delta V_{\text {feed, } t}}$

$\Delta V_{\text {feed }, t}=\frac{M_{\text {draw }, t}-M_{\text {draw }, 0}}{\rho_{\text {water }}}$

$V_{\text {draw }, t}=V_{\text {draw }, 0}+\Delta V_{\text {feed }, t}$

where $\mathrm{J}_{\mathrm{N}}$ is the normalized flux; $\mathrm{J}_{\mathrm{t}}$ is the water flux at time $t ; \mathrm{J}_{0}$ is the initial water flux; DF is the dilution factor; $\Delta \mathrm{V}_{\text {feed,t }}$ is the volume of permeated feed solution during $t$ hour; $M_{\text {draw, }}$ is the weight of draw solution at time $t$; and $M_{\text {draw }, 0}$ is the weight of draw solution at initial time. $V_{\text {draw }, t}$ is the volume of draw solution at time $t ; \rho_{\text {water }}$ is the density of water. 
Thus, the rejection of $\mathrm{PhACs}$ is calculated by the following equation:

$$
R(\%)=\left[1-\frac{D F \times C_{d r a w, t}}{C_{\text {feed }, t}}\right] \times 100
$$

257 The reverse flux of draw solute $\mathrm{J}_{\text {salt }}$ is calculated by the mass balance calculation:

$J_{\text {salt }}=\frac{\left(C_{t} V_{\text {feedt }}-C_{0} V_{\text {feed } 0}\right)}{A t}$

$V_{\text {feedt }}=V_{\text {feed } 0}-\Delta V_{p, t}$

where $C_{0}$ and $C_{t}$ are the concentrations of the draw solute in the feed at initial time 0 and time $t$, respectively. $V_{\text {feed, } 0}$ and $V_{\text {feed,t }}$ are the volumes of the feed at initial time and time $t$, respectively. $\mathrm{A}$ is the effective membrane area.

\subsection{Analytical methods}

The concentrations of sulfamethoxazole and carbamazepine in the feed and draw solution were analyzed by an HPLC system (Shimadzu, Kyoto, Japan). The system was equipped with a Supelco Drug Discovery C18 column (with a diameter, length, and pore size of $4.6 \mathrm{~mm}, 150 \mathrm{~mm}$ and $5 \mu \mathrm{m}$, respectively) and a UV-Vis detector. The detection wavelength used was $280 \mathrm{~nm}$. The mobile phase composed of acetonitrile and Milli-Q water buffered with $25 \mathrm{mM} \mathrm{KH}_{2} \mathrm{PO}_{4}$. Eluent A $(80 \%$ acetonitrile $+20 \%$ buffer, v/v) and Eluent B (20\% acetonitrile $+80 \%$ buffer $)$ were delivered at $0.8 \mathrm{~mL} / \mathrm{min}$ through the column in time-dependent gradient for 30 mins. The sample injection volume of $50 \mu \mathrm{L}$ was used. The coefficient of determination $\left(\mathrm{R}^{2}\right)$ of the calibration was above 0.99 . The limit of quantification for both sulfamethoxazole and carbamazepine under these conditions was $10 \mu \mathrm{g} / \mathrm{L}$.

Conductivities of the feed and draw solutions were measured using an Orion 4-Star plus conductivity meter (Thermo Fisher Scientific, Waltham, MA). A $\mathrm{V}_{\mathrm{CSH}}$ TOC analyzer (Shimadzu, Kyoto, Japan) was used for TOC concentration measurement.

Molecular weight distribution of each organic foulant was analyzed by liquid chromatography with organic carbon detection (LC-OCD) (Model 8, DOC-Labor, Karlsruhe, Germany). The 
concentrations of dissolved organic carbon (DOC) of three samples were approximate $1 \mathrm{mg} / \mathrm{L}$, which were analyzed by A VCSH TOC analyzer (Shimadzu, Kyoto, Japan). All samples were filtered through $0.45 \mu \mathrm{m}$ filter paper prior to analysis. The physical description and method of LC-OCD analysis have been previously published by Huber et al. (Huber et al. 2011). The customized software (ChromCALC, DOC-LABOR, Karlsruhe, Germany) was used to acquire data and process data.

\section{Results and discussion}

\subsection{Membrane transport parameters}

The separation performance of the FO process is dependent on the membrane transport parameters, including A, B, and S value. These transport parameters of the TFC FO membrane in this study were characterized and compared to those from commercially available membranes, such as cellulose triacetate (CTA) FO membranes (Table 2). CTA FO membrane is composed of a cellulose triacetate active layer with an embedded woven support layer. Results in Table 2 show that this TFC FO membrane has a significantly higher A value and slightly higher B value than the CTA membranes from Hydration Technology Innovations (HTI, Albany, OR). On the other hand, the TFC FO membrane in this study has lower performance parameters in terms of both A and B values compared to the TFC FO membrane from HTI. In addition, the TFC FO membrane in this study has a lower $\mathrm{S}$ value than the other commercial membranes shown in Table 2. A low $\mathrm{S}$ value is desirable as it results in a less severe internal concentration polarization (ICP) effect (Han et al. 2012, Liang et al. 2017), thus, a higher flux and solute rejection (Alturki et al. 2013, Xie et al. 2014b). Overall, the results in Table 2 suggest that the TFC FO membrane used in this study is comparable to other currently available in terms of key performance parameters. 
Table 2 Comparison of key transport parameters between the TFC FO membrane used in this study and several other FO membranes currently available in the market The experimental conditions were as follows: For A and B value, DI water and $\mathrm{NaCl}(2 \mathrm{~g} / \mathrm{L})$ as feed solution in cross flow RO setup, applied hydraulic pressure $=10$ bar, cross flow velocity $=25 \mathrm{~cm} / \mathrm{s}$. For $\mathrm{S}$ value, $\mathrm{NaCl}(0.5 \mathrm{M})$ as draw solution and DI water as feed solution in cross flow FO setup (average \pm standard deviation from duplicate experiments) $\left({ }^{1}\right.$ from Xie et al., (2014b); ${ }^{2}$ from Luo et al., (2016)).

\begin{tabular}{|c|c|c|c|c|}
\hline \multirow[t]{2}{*}{ Membrane } & \multicolumn{3}{|c|}{ Literature } & This study \\
\hline & CTA $^{1}$ & $\mathrm{CTA}^{2}$ & $\mathrm{TFC}^{\mathrm{I}}$ & TFC \\
\hline $\begin{array}{l}\text { Pure water permeability, } \\
\text { A }\left(\mathrm{L} \cdot \mathrm{m}^{-2} \cdot \mathrm{h}^{-1} \cdot \mathrm{bar}^{-1}\right)\end{array}$ & $0.65 \pm 0.03$ & $0.84 \pm 0.03$ & $4.70 \pm 0.16$ & $3.20 \pm 0.22$ \\
\hline $\begin{array}{l}\text { Salt }(\mathrm{NaCl}) \text { permeability } \\
\text { coefficient, } \mathrm{B}\left(\mathrm{L} \cdot \mathrm{m}^{-2} \cdot \mathrm{h}^{-1}\right)\end{array}$ & $0.25 \pm 0.07$ & $0.32 \pm 0.06$ & $0.16 \pm 0.03$ & $0.41 \pm 0.01$ \\
\hline $\begin{array}{l}\text { Membrane structural } \\
\text { parameter, } \mathrm{S}(\mathrm{mm})\end{array}$ & $0.67 \pm 0.13$ & $0.57 \pm 0.02$ & $0.52 \pm 0.11$ & $0.46 \pm 0.05$ \\
\hline
\end{tabular}

\subsection{Membrane average pore radius}

Steric hindrance is expected to be the key rejection mechanism of PhACs. Thus, it is imperative to determine the membrane pore radius. The TFC FO membrane used in this study has an estimated pore radius of $0.37 \mathrm{~nm}$ (Table 3), which is similar to that of the CTA membranes from HTI (Table 4). Nevertheless, the TFC FO membrane used in this study shows higher water permeability (A value) as can be seen in Table 2. On the other hand, the pore radius of the TFC membrane in this study is smaller than that of the TFC polyamide FO from HTI. In agreement with this pore size observation, the membrane investigated here also shows lower water permeability (A value) compared to the TFC FO membrane from HTI.

Table 3 Estimated average membrane pore radii of the clean FO membrane. The experimental conditions were as follows: The membranes were compact for $3 \mathrm{~h}$ at the $10 \mathrm{bar}$. The concentration of each organic solute in DI water is $40 \mathrm{mg} / \mathrm{L}$. Subsequent experiments were conducted at 5, 6, 8, 10 and 12 bar with a cross-flow velocity of $25 \mathrm{~cm} / \mathrm{s}$.

\begin{tabular}{ccccc}
\hline Test & Organic solute & Solute size $\mathrm{r}_{\mathrm{s}}(\mathrm{nm})$ & $\lambda=\mathrm{r}_{\mathrm{s}} / \mathrm{r}_{\mathrm{m}}$ & Pore radius $\mathrm{r}_{\mathrm{m}}(\mathrm{nm})$ \\
\hline 1 & Glucose & 0.32 & 0.790 & 0.41 \\
2 & & 0.32 & 0.769 & 0.42 \\
1 & Xylose & 0.29 & 0.824 & 0.35 \\
\hline
\end{tabular}




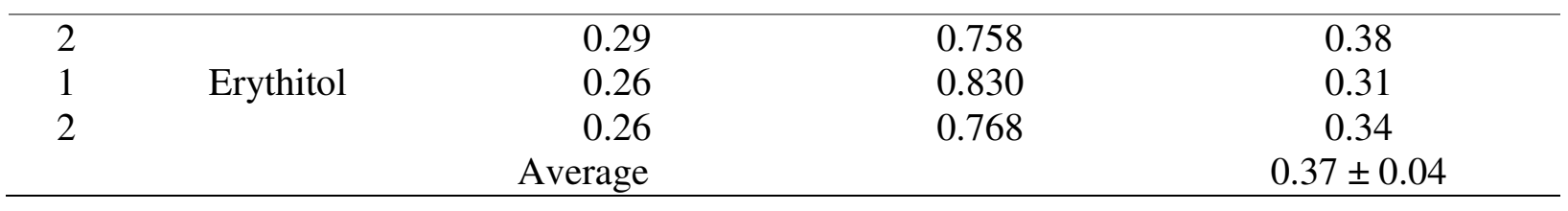

Table 4 Calculated average membrane pore radii of the CTA and TFC FO membrane active layers ( ${ }^{1}$ from Xie et al., (2014b); ${ }^{2}$ from Luo et al., (2016)).

\begin{tabular}{ccccc}
\hline & \multicolumn{3}{c}{ Literature } & This study \\
\hline Pore radius $\mathrm{r}_{\mathrm{p}}$ & $\mathrm{CTA}^{1}$ & $\mathrm{CTA}^{2}$ & $\mathrm{TFC}^{1}$ & $\mathrm{TFC}$ \\
$(\mathrm{nm})$ & 0.37 & 0.34 & 0.42 & 0.37 \\
\hline
\end{tabular}

\subsection{Organic characterization of model organic foulants by LC-OCD}

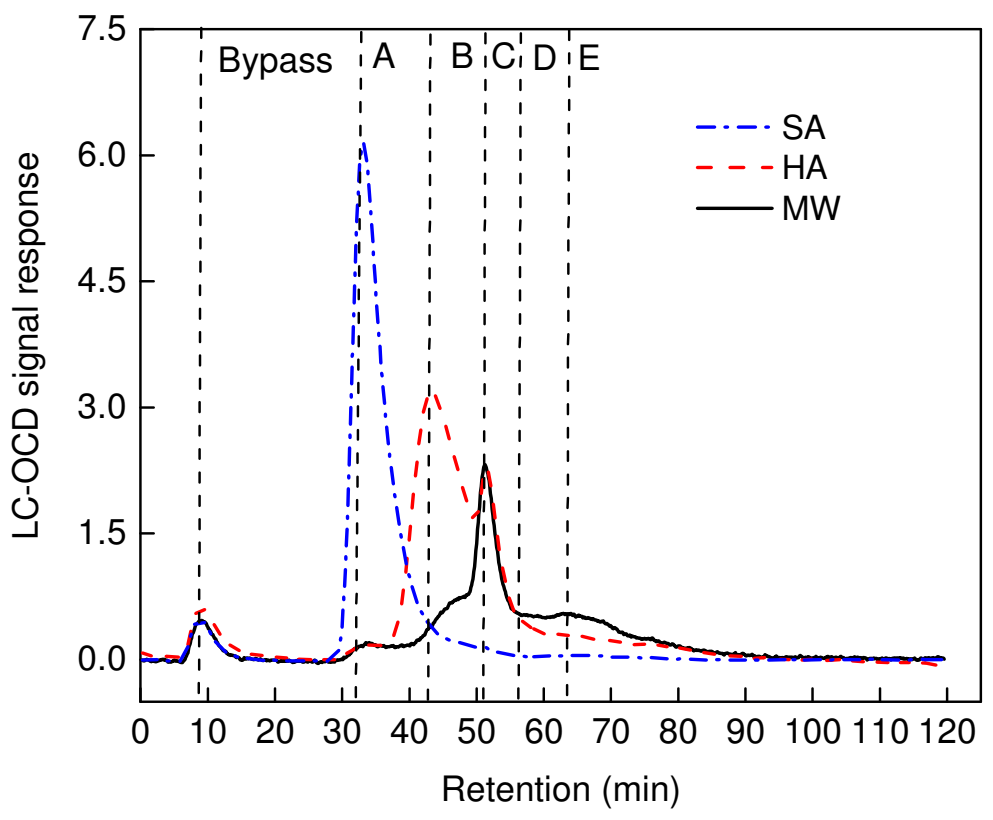

Fig. 2 LC-OCD chromatograms of sodium alginate (SA) and humic acid (HA) solutions and municipal wastewater (MW). Fraction A: biopolymer, Fraction B: humic substances, Fraction C: building blocks, Fraction D: low molecular weight acids, Fraction E: low molecular weight neutrals.

The molecular weight distributions of the organic matter in wastewater and model foulant solutions were determined by size exclusion chromatography using LC-OCD (Fig. 2). The organic matter was eluted successively based on the molecular size, namely fraction A: biopolymers $(\geq 20,000$ Da including proteins, protein-like material, polysaccharides, 
polysaccharide-like material, amino sugars), fraction B: humic substances (1000 - 20,000 Da), fraction C: building blocks (breakdown products of humic substances, 350 - $500 \mathrm{Da}$ ), fraction D low molecular weight (LMW) acids (<350 Da, which are anions at the neutral $\mathrm{pH}$ of the buffer), fraction E: LMW neutrals (<350 Da, which are hydrophilic in nature) (Huber et al. 2011).

Building blocks and LMW matter (both acids and neutrals) are the two most prevalent organic fractions in municipal wastewater (Fig. 2). The estimated contents of these fractions in municipal wastewater are biopolymer (3.6\%), building blocks (21.6\%), LMW neutrals (29.1\%), LMW acids (11.6\%). Municipal wastewater contains more LMW matter than the other two model foulant solutions, thus a more compact fouling layer and more severe flux decline can be observed. This is discussed in more detail in section 3.5.

Biopolymers contribute $68.1 \%$ of the total DOC in sodium alginate. The other fractions found were building blocks (26.1\%), LMW neutrals $(2.1 \%)$ and LMW acids $(0.1 \%)$. Sodium alginate consists of mostly polysaccharides, which is a good representative of extracellular polymeric substances (Flemming et al. 2007). This suggests that alginate solution can also induce considerable fouling due to the interaction between polysaccharides and calcium. For humic acid, the peaks of humic substances and building blocks peaks are more obvious than biopolymer and LMW neutrals. The estimated contents of these contents are humic substances (45.2\%), building blocks (25.1\%), LMW neutrals (12.5\%) and biopolymer (1.7\%). Compared to LMW neutrals, humic substances is expected to form a less compact fouling layer, thus less severe the flux decline.

\subsection{Impact of fouling on membrane surface charge and hydrophobicity}

Membrane fouling leads to significant changes in the membrane surface charge (Fig. 3). In all cases, the fouled membranes became less negative than the clean membrane. Municipal wastewater shows the most significant impact on zeta potential, followed by sodium alginate and the humic acid foulant solutions. A possible explanation for this is the abundance of $\mathrm{Mg}^{2+}$ and $\mathrm{Ca}^{2+}$ in wastewater neutralizes the negatively charged adsorption of organic molecules to the membrane surface (Valladares Linares et al. 2011). 
It has been established that organic foulants particularly sodium alginate can form a cationstabilized gel, dubbed the "egg-box" shaped gel (Jin et al. 2009). Thus, cations such as $\mathrm{Mg}^{2+}$ and $\mathrm{Ca}^{2+}$ in wastewater can adsorb into an organic fouling layer rendering the membrane surface less negative as can be seen in Fig. 3. Results of this study also illustrate that the impact of fouling on the surface charge is dependent on the membrane materials. Indeed, Xie et al., (Xie et al. 2013a) examined the impact of organic fouling on surface charge using a CTA FO membrane. Unlike the polyamide material which is abundant in uncross-linked carboxylic functional groups (and thus is highly negatively charged), the CTA FO membrane used by them was neutral under a clean condition. They also observed that humic acid fouling rendered the membrane surface more negatively charged.

The effect of different foulants on the membrane surface can also be examined by changes in contact angle of the membrane surface. In general, the presence of the fouling layer makes the membrane surface more hydrophobic (Table 5). Increasing membrane hydrophobicity resulted in a higher fouling propensity because of the increase in hydrophobic interaction between the foulant and the membrane surface. As can be seen in Table 5, municipal wastewater significantly increased the membrane surface hydrophobicity. The presence of polysaccharides and humic substance in municipal wastewater promoted surface hydrophobicity through adsorbed organic molecules on the active layer (Jin et al. 2009). Sodium alginate also increases the hydrophobicity of the active layer significantly. This would suggest that the increasing hydrophobicity is due to the interaction between high carboxylate functionality of sodium alginate and $\mathrm{Ca}^{2+}$ (Jin et al. 2009). However, changes in the active layer hydrophobicity caused by humic acid fouling are insignificant.

There was a notable decrease of the hydrophobicity of the support layer after sodium alginate fouling. These results are rather unexpected since the supporting layer is not in contact with the feed solution. It may imply that some components from the fouling layer migrate to the support layer, thus interfering the hydrophobicity of support layer. However, other fouling tests showed both humic acid and municipal wastewater resulted in the discernible changes of hydrophobicity in support layer. Further work is required to explain these phenomena. 


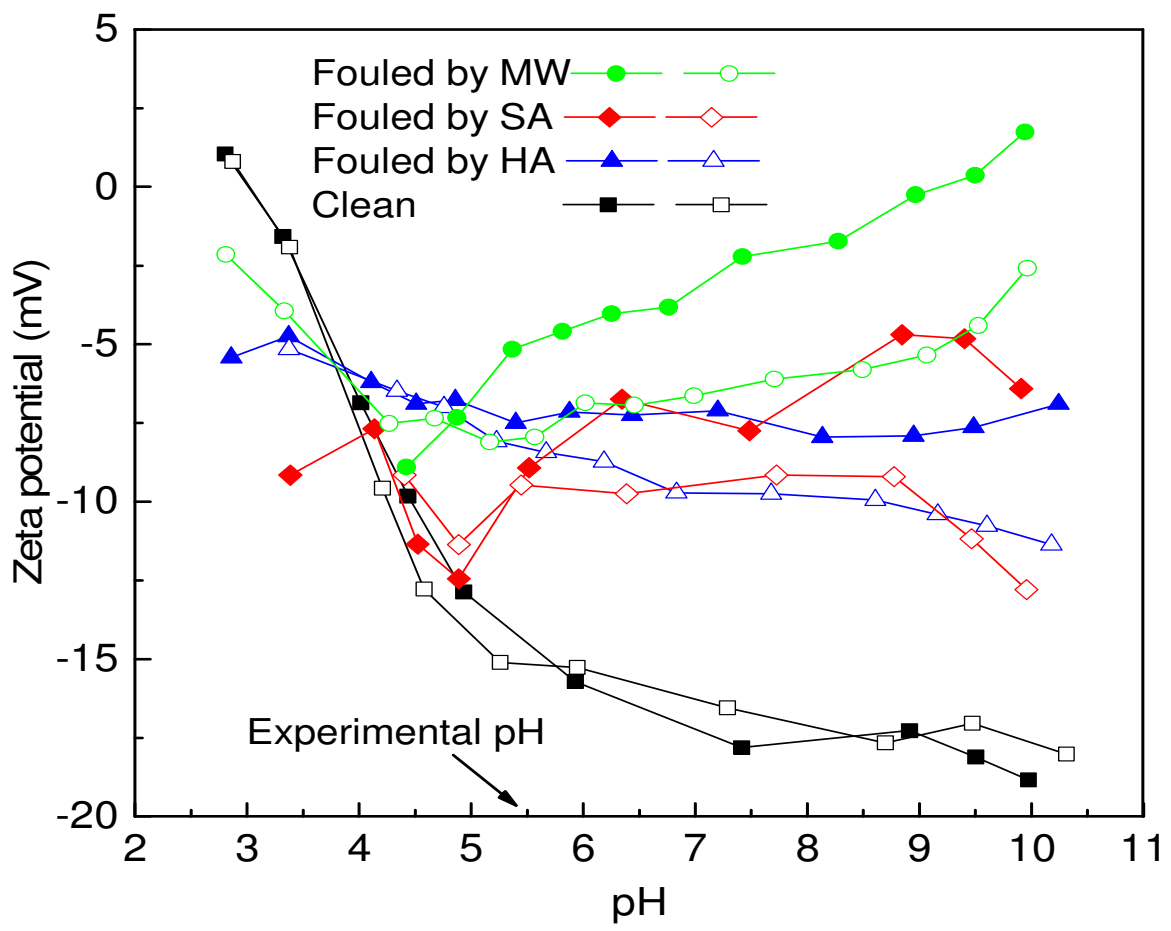

Fig. 3 Zeta potential of the active layer of membrane samples. FO experimental conditions were as follows: For feed solution, the concentration of each model organic solutes is $200 \mathrm{mg} / \mathrm{L}$ except municipal wastewater. Background electrolyte contained $1 \mathrm{mM} \mathrm{CaCl}_{2} . \mathrm{NaCl}(0.5 \mathrm{M})$ as draw solution, initial feed solution $\mathrm{pH}=5.5$, operation time $=20 \mathrm{~h}(\mathrm{HA}: 200 \mathrm{mg} / \mathrm{L}$ humic acid +1 $\mathrm{mM} \mathrm{CaCl} 2$; SA: $200 \mathrm{mg} / \mathrm{L}$ sodium alginate $+1 \mathrm{mM} \mathrm{CaCl}_{2} ; \mathrm{MW}$ : municipal wastewater. Each membrane sample was analyzed in replicate).

Table 5 Comparison of the contact angle of membrane layers in the different feed conditions.

The experimental conditions are described in Fig. 3 (average \pm standard deviation from duplicate experiments).

\begin{tabular}{ccc}
\hline \multirow{2}{*}{ Feed condition } & \multicolumn{2}{c}{ Contact angle $\left(^{\circ}\right)$} \\
\cline { 2 - 3 } & Active layer & Support layer \\
\hline DI water & $49.5 \pm 3.4$ & $56.2 \pm 0.1$ \\
Humic acid $+0.1 \mathrm{mM} \mathrm{CaCl}_{2}$ & $47.0 \pm 3.6$ & $66.8 \pm 1.5$ \\
Sodium alginate $+0.1 \mathrm{mM} \mathrm{CaCl}_{2}$ & $73.2 \pm 4.8$ & $39.7 \pm 2.1$ \\
Municipal wastewater & $82.0 \pm 2.2$ & $60.7 \pm 3.5$ \\
\hline
\end{tabular}




\subsection{Impact of fouling on water and reverse salt flux}

409

410

411

412

413

414

415

416

417

418

419

420

421

422

423

424

425

426

427

428

429

430

431

432

433

434

435

436

437

438

The effect of fouling on the membrane performance can be assessed in terms of water flux and reverse salt flux. The flux decline is attributed to the coupled concentration polarization and fouling layer. Indeed, a small flux decline about $20 \%$ was observed when a DI water was used as the feed (Fig. 4a). During all FO experiments, the draw solution concentration was constant, however, the feed osmotic pressure increased gradually due to the reverse salt flux. On the other hand, the water flux through the membrane dilutes the concentration of the draw solution inside the membrane support layer. Thus, the small decrease in water flux can be explained by the loss of effective osmotic driving force (McCutcheon \&Elimelech 2006, Tang et al. 2010).

In contrast to the small flux decline observed with a clean feed solution, significant membrane fouling could be seen with all fouling solutions. The severity of the flux decline was in decreasing order of municipal wastewater, alginate solution, and humic acid solution (Fig. 4b-d). This is consistent with the molecular weight distribution of organic matter within these solutions as discussed in section 3.3. When municipal wastewater was used as the feed, a $70 \%$ flux decline was observed at the end of the experiment (Fig. 4d). The flux decline profile when the membrane was fouled with municipal wastewater also differs markedly from the much more gradual flux decrease when DI water was used as the clean feed solution. With municipal wastewater, a sharp flux decline was observed in the first $4 \mathrm{~h}$ of the experiment followed by a more gradual flux decline. On the other hand, flux decline caused by the increase in feed osmotic pressure when a clean feed solution was used was linear throughout the experiment (Fig. 4a). The municipal wastewater consists of large amounts of building blocks and LMW neutrals (section 3.3). Thus, these foulants form a more compact and dense fouling layer during the FO process (Boo et al. 2013). The large flux decline is attributed to the increased hydraulic resistance of the fouling layer (with the assumption that fouling layer reduces the water permeability but it does not change the salt permeability) (Tang et al. 2010).

Notable membrane fouling could also be observed when $200 \mathrm{mg} / \mathrm{L}$ of either alginate or humic acid was used as the feed solution (Fig. 4b-c). Alginate forms a gel layer on the FO membrane surface. This may be due to calcium ions in the feed solution making a strong bond between alginate molecules through the formation of cross-linking between calcium ions and carboxyl groups on the surface of alginate. The normalized flux decline caused by sodium alginate (Fig. $4 \mathrm{~b}$ ) is less severe than that caused by municipal wastewater in this study. Compared to the 
municipal wastewater, sodium alginate contains more biopolymers and less LMW neutral fractions (section 3.3). Thus sodium alginate may form a less compact fouling layer than municipal wastewater. On the other hand, humic acid naturally has more humic substances and less LMW neutral fractions than municipal wastewater (section 3.3). Despite the deposition from interaction between carboxylate or phenolic hydroxyl group and $\mathrm{Ca}^{2+}$ on the membrane surface, humic acid forms a relatively less compact fouling layer than municipal wastewater as well. However, a notable flux decline was also observed during the fouling test (Fig. 4c). A plausible explanation for this is because of the smaller ICP effect in this configuration (Tang et al. 2010).
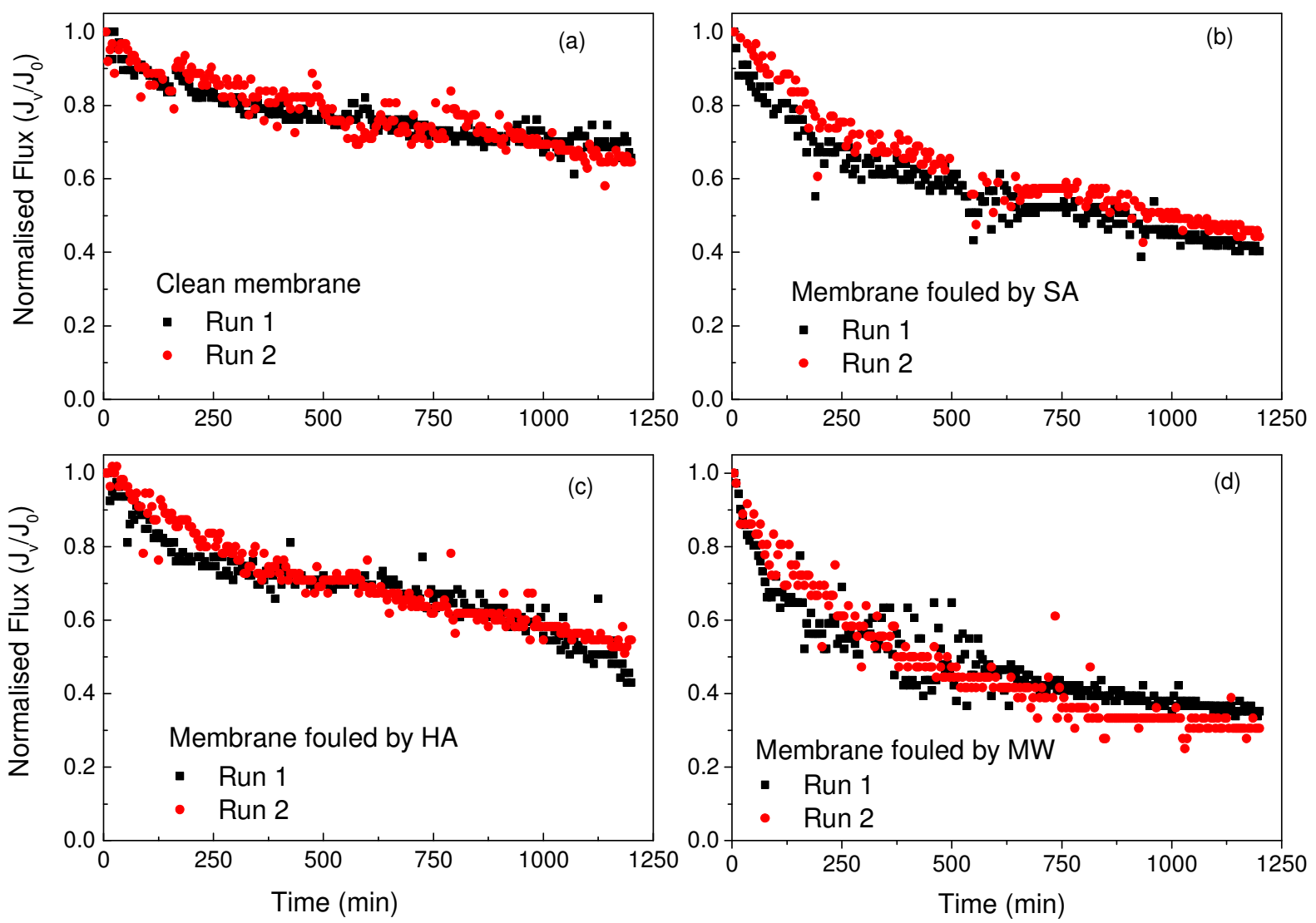

Fig. 4 Water flux of the membrane at the presence of different foulant as a function of time (a) DI water; (b) SA: $200 \mathrm{mg} / \mathrm{L}$ sodium alginate $+1 \mathrm{mM} \mathrm{CaCl}_{2}$; (c) HA: $200 \mathrm{mg} / \mathrm{L}$ humic acid +1 $\mathrm{mM} \mathrm{CaCl}_{2}$; (d) Municipal wastewater (MW). The experimental conditions are described in the caption of Fig. 3. 


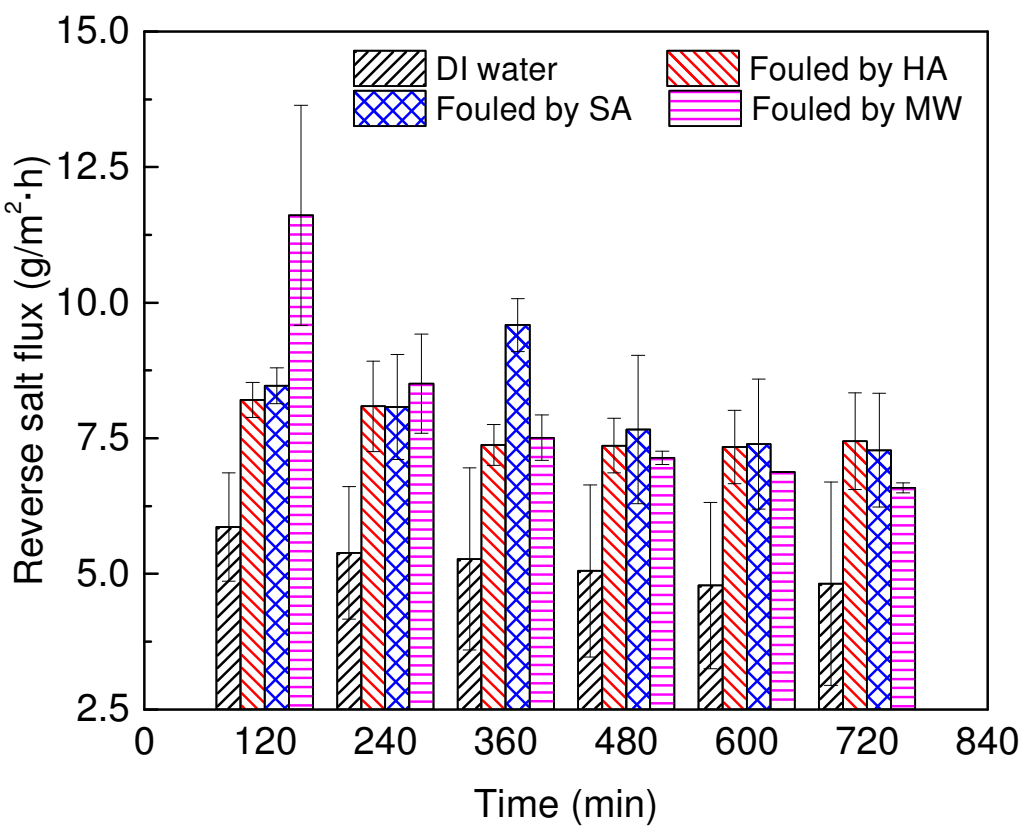

Fig. 5 The reverse salt flux of the membrane at the presence of different foulant as a function of time in feed solution. The experimental conditions are described in Fig. 3 (HA: 200 mg/L humic acid $+1 \mathrm{mM} \mathrm{CaCl}_{2} ; \mathrm{SA}: 200 \mathrm{mg} / \mathrm{L}$ sodium alginate $+1 \mathrm{mM} \mathrm{CaCl}_{2} ; \mathrm{MW}$ : municipal wastewater. Error bars represent standard deviation from duplicate experiments).

Bidirectional diffusion, namely forward diffusion (from feed to draw) and reverse diffusion (from draw to feed), is intrinsic in the FO process. The reverse diffusion of draw solute is related to several aspects, including the type of draw and feed solutes, their concentrations and crossflow velocities. The difference between reverse salt fluxes in Fig. 5 is associated with feed solutes since it is the only variable here.

The observed reverse salt fluxes in all the membranes decrease as the function of water flux and time (Fig. 4, 5). The highest reverse salt flux is observed with municipal wastewater at the beginning of the experiment after which there is a notable decline as a function of time (Fig. 5). This observation is consistent with the rapid water flux decline observed in Fig. 4. The coupling effect of membrane fouling and ICP reduces the effective osmotic pressure, leading to a decreasing water flux as well as reverse salt flux simultaneously (Phillip et al. 2010). Corresponding to the gradual decline in water flux, a small but discernible decline in reverse salt flux as a function of time was also observed with humic acid and sodium alginate fouled membranes. Hancock and Cath (Hancock \&Cath 2009) suggested that the reverse diffusing draw 
solutes are concentrated at the CTA membrane surface facing feed solution and the concentration boundary layer on the draw solution side of the membrane is not well mixed and remains diluted at lower and equal flow velocities. Thus, these two phenomena resulted in diminishing chemical potential gradient between draw and feed solutions and reduce both water and reverse salt fluxes.

It is interesting that the reverse salt flux of the fouled membranes (either by a model foulant or municipal wastewater) was considerably higher than that under a clean (non-fouling) condition. This can be attributed to the cake enhance concentration polarization within the thin cake layer on the feed side. The fouling cake layer on the membrane can be considered as part of the supporting layer. As a result, the effective structure parameter (S) of the membrane increases because of fouling, leading to an increase in reverse salt flux.

\subsection{Impact of fouling on the removal of $\mathrm{PhACs}$}

In general, the removal of an organic molecule by FO is controlled by steric hindrance (i.e. size exclusion), charge exclusion (i.e. electrostatic repulsion), and the sorption-diffusion mechanism within the membrane polymeric matrix (Coday et al. 2014). In this study, the $\mathrm{pH}$ of all feed solution was adjusted to $\mathrm{pH} 5.5$ which is the $\mathrm{pH}$ of the municipal wastewater. At $\mathrm{pH} 5.5$, carbamazepine and over $90 \%$ of sulfamethoxazole exist as neutral species. As a result, separation of sulfamethoxazole and carbamazepine are primarily governed by steric hindrance. Since the molecular dimensions of sulfamethoxazole and carbamazepine are considerably larger than the estimated membrane pore size (Table 3), as expected, high rejection of both sulfamethoxazole and carbamazepine was observed under all experimental conditions in this study (Fig. 6, 7). Nevertheless, the results do show a clear effect of membrane fouling on the rejection of these two PhACs.

The role of steric hindrance in the rejection of sulfamethoxazole can be observed in Fig. 6. All fouled membranes show the higher rejection of sulfamethoxazole than the clean membrane. Decreased pore size caused by introduced $\mathrm{Ca}^{2+}$ with each model organic foulant hinders the transport of sulfamethoxazole (Nghiem \&Hawkes 2007, Xie et al. 2013a). It is also notable that rejection of fouled membrane caused by municipal wastewater is lower than that observed with the humic acid and alginate fouled membranes. As a possible explanation for this, the 
500

501

502

503

504

505

506

507

508

509

510

511

512

513

514

hydrophobic organic fouling layer can interfere with the separation of sulfamethoxazole and thus disrupts the diffusion of this compound through membrane.

The separation behaviors of carbamazepine by clean and fouled membranes differ markedly from one another (Fig. 7). Fouling has a negative impact on the rejection of carbamazepine and the rejection by the clean membrane is higher than for the three fouled ones. Compared to the rejection of sulfamethoxazole by fouled FO membranes, this result is likely due to the cake enhanced concentration polarization which results in an elevated concentration of the solutes within the fouling layer (Nghiem et al. 2010).

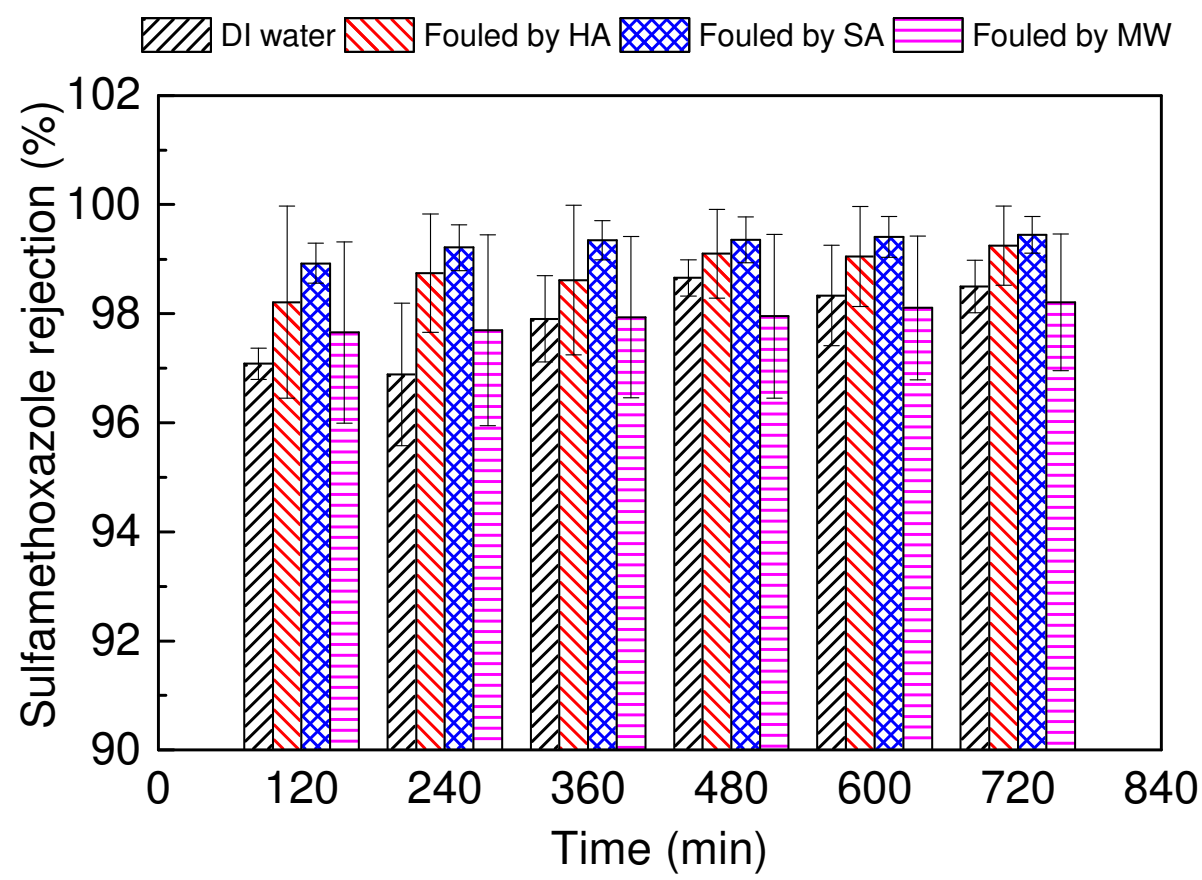

Fig. 6 Sulfamethoxazole rejection by the clean and fouled membrane as a function of time. The FO experimental conditions are described in Fig. 3. The concentration of each PhACs in feed solution is $2 \mathrm{mg} / \mathrm{L}$ (HA: humic acid $+1 \mathrm{mM} \mathrm{CaCl}_{2}$; $\mathrm{SA}$ : sodium alginate $+1 \mathrm{mM} \mathrm{CaCl}_{2}$; $\mathrm{MW}$ : municipal wastewater. Error bars represent standard deviation from duplicate experiments). 


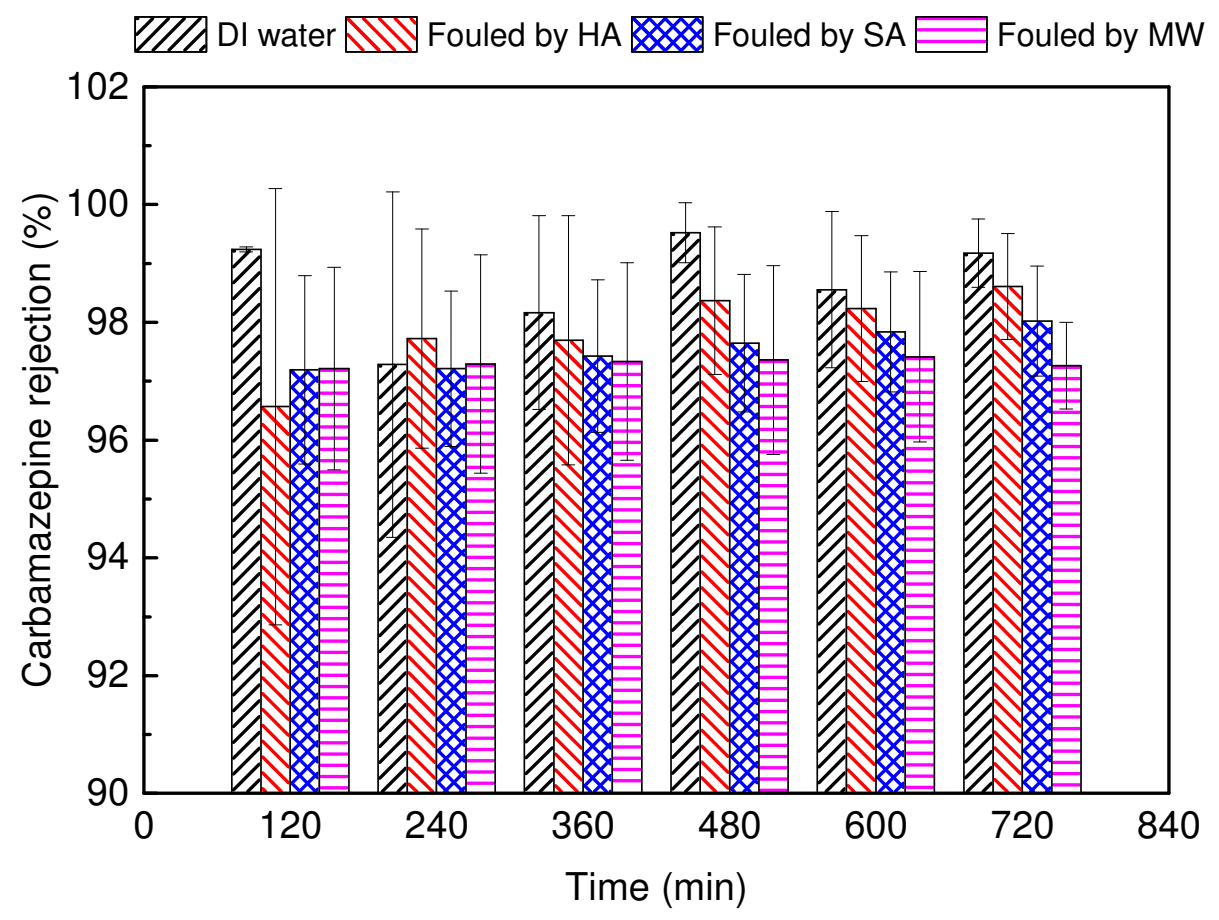

515

516

517

518

519

520

521

522

523

524

525

526

527

528

529

530

531

Fig. 7 Carbamazepine rejection by the clean and fouled membrane as a function of time. The FO experimental conditions are described in Fig. 6. (HA: humic acid $+1 \mathrm{mM} \mathrm{CaCl}_{2}$; SA: sodium alginate $+1 \mathrm{mM} \mathrm{CaCl}_{2}$; MW: municipal wastewater. Error bars represent standard deviation from duplicate experiments).

\section{Conclusion}

Results reported here indicate that membrane fouling results in notable changes in the membrane properties in terms of the membrane surface charge and hydrophobicity. LC-OCD analysis shows that membrane fouling behavior is governed by the composition of the feed solution. Water flux and reverse salt flux are affected by the fouling layer and internal concentration polarization. Furthermore, membrane fouling can exert a considerable effect on the separation process of carbamazepine and sulfamethoxazole. Fouled membranes caused by different organic fractions exhibit quite different rejection behavior for sulfamethoxazole and carbamazepine which were selected as model PhACs in this study. Both PhACs were well rejected by clean and fouled FO membranes. Membrane fouling results in an increase in sulfamethoxazole rejection, whilst carbamazepine rejection decreases due to membrane fouling. Since only one membrane was used in this study, these findings may not necessarily applicable to other membrane 
materials such as cellulose triacetate. Further research to investigate the impact of membrane cleaning on the removal of PhACs by FO is also recommended.

\section{Acknowledgements}

The Chinese Scholarship Council and University of Wollongong, Australia are gratefully acknowledged for $\mathrm{PhD}$ scholarship support to Lei Zheng.

\section{Reference}

Aftab B, Khan SJ, Maqbool T, Hankins NP (2015): High strength domestic wastewater treatment with submerged forward osmosis membrane bioreactor. Water Science and Technology 72, 141-149

Alturki AA, McDonald JA, Khan SJ, Price WE, Nghiem LD, Elimelech M (2013): Removal of trace organic contaminants by the forward osmosis process. Separation and Purification Technology 103, 258-266

Boo C, Elimelech M, Hong S (2013): Fouling control in a forward osmosis process integrating seawater desalination and wastewater reclamation. Journal of Membrane Science 444, $148-156$

Bungay PM, Brenner H (1973): The motion of a closely-fitting sphere in a fluid-filled tube. International Journal of Multiphase Flow 1, 25-56

Carlson JC, Anderson JC, Low JE, Cardinal P, MacKenzie SD, Beattie SA, Challis JK, Bennett RJ, Meronek SS, Wilks RPA, Buhay WM, Wong CS, Hanson ML (2013): Presence and hazards of nutrients and emerging organic micropollutants from sewage lagoon discharges into Dead Horse Creek, Manitoba, Canada. Science of The Total Environment 445-446, 64-78

Cath TY, Elimelech M, McCutcheon JR, McGinnis RL, Achilli A, Anastasio D, Brady AR, Childress AE, Farr IV, Hancock NT, Lampi J, Nghiem LD, Xie M, Yip NY (2013): Standard Methodology for Evaluating Membrane Performance in Osmotically Driven Membrane Processes. Desalination 312, 31-38

Chang H-M, Chen S-S, Nguyen NC, Chang W-S, Sinha Ray S (2017): Osmosis membrane bioreactor-microfiltration with magnesium-based draw solute for salinity reduction and phosphorus recovery. International Biodeterioration \& Biodegradation 124, 169-175

Chen Z-F, Ying G-G (2015): Occurrence, fate and ecological risk of five typical azole fungicides as therapeutic and personal care products in the environment: A review. Environment International 84, 142-153

Coday BD, Yaffe BGM, Xu P, Cath TY (2014): Rejection of Trace Organic Compounds by Forward Osmosis Membranes: A Literature Review. Environmental Science \& Technology 48, 3612-3624

D'Haese A, Le-Clech P, Van Nevel S, Verbeken K, Cornelissen ER, Khan SJ, Verliefde ARD (2013): Trace organic solutes in closed-loop forward osmosis applications: Influence of membrane fouling and modeling of solute build-up. Water Research 47, 5232-5244

Elimelech M, Chen WH, Waypa JJ (1994): Measuring the zeta (electrokinetic) potential of reverse osmosis membranes by a streaming potential analyzer. Desalination 95, 269-286 
Flemming H-C, Neu TR, Wozniak DJ (2007): The EPS Matrix: The "House of Biofilm Cells". Journal of Bacteriology 189, 7945-7947

Han G, Chung T-S, Toriida M, Tamai S (2012): Thin-film composite forward osmosis membranes with novel hydrophilic supports for desalination. Journal of Membrane Science 423, 543-555

Hancock NT, Cath TY (2009): Solute Coupled Diffusion in Osmotically Driven Membrane Processes. Environmental Science \& Technology 43, 6769-6775

Hernando MD, Mezcua M, Fernández-Alba AR, Barceló D (2006): Environmental risk assessment of pharmaceutical residues in wastewater effluents, surface waters and sediments. Talanta 69, 334-342

Huber SA, Balz A, Abert M, Pronk W (2011): Characterisation of aquatic humic and non-humic matter with size-exclusion chromatography - organic carbon detection - organic nitrogen detection (LC-OCD-OND). Water Research 45, 879-885

Jin X, Huang X, Hoek EMV (2009): Role of Specific Ion Interactions in Seawater RO Membrane Fouling by Alginic Acid. Environmental Science \& Technology 43, 35803587

Lee S, Boo C, Elimelech M, Hong S (2010): Comparison of fouling behavior in forward osmosis (FO) and reverse osmosis (RO). Journal of Membrane Science 365, 34-39

Liang H-Q, Hung W-S, Yu H-H, Hu C-C, Lee K-R, Lai J-Y, Xu Z-K (2017): Forward osmosis membranes with unprecedented water flux. Journal of Membrane Science 529, 47-54

Liyanaarachchi S, Jegatheesan V, Muthukumaran S, Gray S, Shu L (2016): Mass balance for a novel RO/FO hybrid system in seawater desalination. Journal of Membrane Science 501, 199-208

Luo W, Xie M, Hai FI, Price WE, Nghiem LD (2016): Biodegradation of cellulose triacetate and polyamide forward osmosis membranes in an activated sludge bioreactor: Observations and implications. Journal of Membrane Science 510, 284-292

Luo W, Phan HV, Li G, Hai FI, Price WE, Elimelech M, Nghiem LD (2017): An Osmotic Membrane Bioreactor-Membrane Distillation System for Simultaneous Wastewater Reuse and Seawater Desalination: Performance and Implications. Environmental Science \& Technology 51, 14311-14320

Luo Y, Guo W, Ngo HH, Nghiem LD, Hai FI, Zhang J, Liang S, Wang XC (2014): A review on the occurrence of micropollutants in the aquatic environment and their fate and removal during wastewater treatment. Science of The Total Environment 473-474, 619-641

McCutcheon JR, Elimelech M (2006): Influence of concentrative and dilutive internal concentration polarization on flux behavior in forward osmosis. Journal of Membrane Science 284, 237-247

McGinnis RL, Elimelech M (2007): Energy requirements of ammonia-carbon dioxide forward osmosis desalination. Desalination 207, 370-382

Nghiem LD, Schäfer AI, Elimelech M (2004): Removal of Natural Hormones by Nanofiltration Membranes: Measurement, Modeling, and Mechanisms. Environmental Science \& Technology 38, 1888-1896

Nghiem LD, Hawkes S (2007): Effects of membrane fouling on the nanofiltration of pharmaceutically active compounds (PhACs): Mechanisms and role of membrane pore size. Separation and Purification Technology 57, 176-184 
Nghiem LD, Coleman PJ (2008): NF/RO filtration of the hydrophobic ionogenic compound triclosan: Transport mechanisms and the influence of membrane fouling. Separation and Purification Technology 62, 709-716

Nghiem LD, Coleman PJ, Espendiller C (2010): Mechanisms underlying the effects of membrane fouling on the nanofiltration of trace organic contaminants. Desalination 250, 682-687

Nguyen NC, Chen S-S, Jain S, Thi NH, Sinha RS, Hao NH, Guo W, Tuan LN, Duong H (2017): Exploration of an innovative draw solution for a forward osmosis-membrane distillation desalination process. Environmental Science and Pollution Research. 25, 52013-5211

Phillip WA, Yong JS, Elimelech M (2010): Reverse Draw Solute Permeation in Forward Osmosis: Modeling and Experiments. Environmental Science \& Technology 44, 51705176

Schwarzenbach RP, Escher BI, Fenner K, Hofstetter TB, Johnson CA, von Gunten U, Wehrli B (2006): The Challenge of Micropollutants in Aquatic Systems. Science 313, 1072-1077

Shannon MA, Bohn PW, Elimelech M, Georgiadis JG, Marĩas BJ, Mayes AM (2008): Science and technology for water purification in the coming decades. Nature 452, 301-310

Simon A, Nghiem LD, Le-Clech P, Khan SJ, Drewes JE (2009): Effects of membrane degradation on the removal of pharmaceutically active compounds (PhACs) by NF/RO filtration processes. Journal of Membrane Science 340, 16-25

Sutzkover I, Hasson D, Semiat R (2000): Simple technique for measuring the concentration polarization level in a reverse osmosis system. Desalination 131, 117-127

Tang CY, She Q, Lay WCL, Wang R, Fane AG (2010): Coupled effects of internal concentration polarization and fouling on flux behavior of forward osmosis membranes during humic acid filtration. Journal of Membrane Science 354, 123-133

Valladares Linares R, Yangali-Quintanilla V, Li Z, Amy G (2011): Rejection of micropollutants by clean and fouled forward osmosis membrane. Water Research 45, 6737-6744

Xie M, Nghiem LD, Price WE, Elimelech M (2012): Comparison of the removal of hydrophobic trace organic contaminants by forward osmosis and reverse osmosis. Water Research 46, 2683-2692

Xie M, Nghiem LD, Price WE, Elimelech M (2013a): Impact of humic acid fouling on membrane performance and transport of pharmaceutically active compounds in forward osmosis. Water research 47, 4567-4575

Xie M, Nghiem LD, Price WE, Elimelech M (2013b): A Forward Osmosis-Membrane Distillation Hybrid Process for Direct Sewer Mining: System Performance and Limitations. Environmental Science \& Technology 47, 13486-13493

Xie M, Nghiem LD, Price WE, Elimelech M (2014a): Impact of organic and colloidal fouling on trace organic contaminant rejection by forward osmosis: Role of initial permeate flux. Desalination 336, 146-152

Xie M, Nghiem LD, Price WE, Elimelech M (2014b): Relating rejection of trace organic contaminants to membrane properties in forward osmosis: Measurements, modelling and implications. Water Research 49, 265-274

Yang S, Hai FI, Price WE, McDonald J, Khan SJ, Nghiem LD (2016): Occurrence of trace organic contaminants in wastewater sludge and their removals by anaerobic digestion. Bioresource Technology 210, 153-159 
Yoon Y, Ryu J, Oh J, Choi B-G, Snyder SA (2010): Occurrence of endocrine disrupting compounds, pharmaceuticals, and personal care products in the Han River (Seoul, South Korea). Science of The Total Environment 408, 636-643 